tion which is accompanied by seasonal on-shore and off-shore movements. But the periodic migrations of the species are markedly interrupted when the call of maturity comes. Then the migration is contranatant, a longer or shorter distance according to species and circumstances, due to the effects of an internal secretion or hormone which exercises a profound influence on the central nervous system, and may also produce somatogenic results. The only invertebrate which is definitely known to react in this way on the approach of spawning is the crabthe females migrate contranatantly at that periodbut it may be presumed that other large, active Crustacea and Cephalopoda respond similarly. Prof. Meek referred to Amphibia as being similarly affected at the spawning season, the hormone bringing about a return to gregariousness as well as somatogenetic effects which characterised the period. The same appears to be true of aquatic reptiles, birds, and mammals, and Prof. Meek suggested that this pointed a wav of approach to the subject of aerial migration. In the discussion following. Prof. Llovd Morgan directed attention to the breeding habits of lapwings, and suggested that thev were to be explained as due to hormone action, and other speakers proposed that attempts should be made to isolate and experiment with the hormone. Prof. Garstang discussed the question with reference to plaice, and Prof. Meek replied, pointing out in this case the distinction between the periodical and the spawning migrations.

\section{Embryological Studies.}

Prof. J. E. Duerden gave an account of the pineal eye of the ostrich (for a summary of this paper see NATURE, vol. iv., pp. 5I6-I7), described a caudal vesicle in ostrich embryos, and recorded the presence of Reissner's fibre. In embryos of about ten days' incubation a prominent vesicular swelling is present at the tip of the tail or on the dorsal surface near the tip. The cavity of the vesicle, in which the central canal of the spinal cord terminates, varies much in size and shape in different specimens. The ventral wall of the spinal cord lines the floor of the cavity and terminates somewhat abruptly, and the dorsal wall of the cord merges gradually into the mesenchymal tissue which constitutes the dorsal and lateral walls of the vesicle, without, however, showing any differentiation into an epithelial laver. The cavity is filled with a coagulable fluid in which cellular tissue in process of degeneration frequently occurs, and occasionally much black pigment is present. 'The external enlargement persists for only a short time, rarely lasting after the twentieth day of incubation. A similar vesicle has been found in several reptiles, and is well-developed in the penguin and the pufiin, though in these it is not so large as in the ostrich. It is suggested that the vesicle in the ostrich, which varies so much in size, is in some way concerned with the regulation of pressure of the cerebro-spinal fluid at this early stage. Longitudinal sections of the caudal region show the presence of Reissner's fibre and its posterior attachment to the mesenchymal tissue. Reissner's fibre has been found to occur within the central canal of the spinal cord of vertebrates from the cyclostomes to the primates.

Mr. J. H. Llovd dealt with the early development of the pronephros in Scyllium and Chrysemys, and supported Mr. Burlend's view that the pronephros arises as a non-segmental groove from the somatic laver of the mesoblast, and that the anterior portion of the duct is formed by constriction from this groove, and not by fusion of the distal ends of tubules. The evidence, as presented by the illustrations, was not convincing, and was subjected to considerab? criticism.

$$
\text { NO. } 2667 \text {, VOL. IO6] }
$$

The Movements of the Sea.

At a joint meeting of Sections D and E, Dr. E. C. Jee gave a paper on the movements of the sea. He pointed out that the temperature of the deep waters surrounding the British Isles is essentially due to the Atlantic circulation. He dealt in some detail with the northern North Sea current, and stated that no significant correlation has yet been demonstrated between the variations of this current and fluctuations in the landings of fish. The current which enters the English Channel from the Atlantic affects the fisheries of the south-west area, and its strength seems to show the following variations: A winter maximum and a summer minimum, and a twoyear, a six-year, and a twelve-year periodicity. It is probable that the fluctuations in the landings of pilchards are correlated with the variations in strength of the Channel current. The periodicities referred to are now being investigated by the International Council. The examination of numerous samples of sea-water and the liberation of surface and bottom drift-bottles are being undertaken with the object of obtaining information for a study of the migrations of mature plaice to and from their spawning-grounds in the Flemish Bight and the probable drift of the pelagic plaice eggs and the location of the fry in their various stages of development.

Prof. E. B. Poulton gave a preliminary account of the hereditary transmission of a minute, extremely variable, and generally asymmetrical marking in the forewing of the currant moth (Abraxas grossulariata).

J. H. Ashworth.

\section{University and Educational Intelligence.}

Birmingham.-At the last meeting of the council the Principal reported that the Staffordshire Educa. tion Committee is increasing its grant to the University from $450 l$. to roool. per annum. The Worcestershire County Council recently increased its annual contribution from $300 l$. to $500 l$.; and the Dudley Town Council has informed the University that it will include an annual sum of $50 \mathrm{l}$. in its estimates.

Messrs. Dorman and Co., of Stafford, have presented a 2o-h.p. petrol engine, and Messrs. Sturge and $\mathrm{Co}$. an old beam engine. The Pro-Vice-Chancellor, Alderman Clayton, is providing rool. towards the cost of removal and re-erection of the latter.

The University is affording facilities in the department of pathology to enable Prof. Shaw Dunn to take part in the training of the Naval and R.A.M.C. personnel required for the physiological department of the Chemical Warfare Section at Porton.

Mr. R. W. W. Sanderson has been appointed a demonstrator in physics for the current session.

Mr. R. G. Abrahams has been appointed honorary assistant curator of the pathological museum, Section of Surgery.

Cambridge.-By the time that this issue appears the vote on the admission of women to membership of the University will have taken place. Both sides are hopeful of the issue, and a fairly close vote is generally anticipated. Something of the vigour of the earlier fighting on this question has vanished, perhaps because the "old guard" realise that they are fighting a losing battle. If they hold their privileged position this time they know that their flanks are in the air, and that it is only a short time before they are liable to be overwhelmed in an attack from another quarter. Somewhat late in the day, many of them are holding out a promise of a place where everybody may go if only the Senate will throw out 
the present proposal. But no details are given, and the fact that some of the signatories in favour of the new and unknown scheme have been on a syndicate for twelve months charged to prepare a suitable scheme, and have so far failed to meet their own and their friends' requirements, does not inspire much confidence in their future operations. The results of the vote and a forecast of the later developments will appear in the next issue of Nature.

Dr. J. N. PRING, reader in electro-chemistry, University of Manchester, has been appointed head of the Physical Chemistry Branch, Research Department, Royal Arsenal, Woolwich.

Sir Richard Gregory will deliver an address on "Scientific Fact and Popular Fallacy" to the students of the Journalism Diploma course at the University of London, South Kensington, S.W.7, on Monday, December ${ }_{3}$, at 5 p.m. The chairman will be Prof. C. H. Lees.

IN connection with the London County Council lectures for teachers, a lecture on "The Antiquity of Man" will be given by Prof. Arthur Keith at the Regent Street Polytechnic, W.I, on Saturday morning, December 18, at 10.30 o'clock. The chair will be taken by Major J. E. K. Studd.

THE University College (University of London) Committee will shortly elect a Quain studentship in biology. The studentship is open to past or present students of the college who have taken a course in botany. The value of the studentship is $1_{5} \mathrm{ol}$. per annum for three years. Candidates should communicate with the Secretary, University College, Gower Street, W.C.I, before December 16 .

THE annual meeting of the Geographical Association will be held at the London Day Training College on Friday and Saturday, January 7 and 8, 1921 . There will be a discussion on Historical Geography, opened by Mr. J. Fairgrieve and Capt. W. W. Jervis, and one on Geography in Continuation Schools, opened by Mr. L. Brooks and Capt. V. A. Bell. Dr. Unstead will lecture on The Study and Teaching of International Relations, and Dr. Haddon on Racial and Cultural Distributions in New Guinea. The presidential address by Prof. Gilbert Murray will be delivered on the afternoon of January 8.

AT a time when almost every university and technical institution in Great Britain has to close its doors to new students because of their already congested condition, it is difficult to believe that any circumstances could justify the extinction of a college which has been a pioneer of the most effective type in the work of technical education. Such, however, is the position of Finsbury Technical College, and a defence committee has been formed to consider the possibility of helping in any way to carry on the work of the college and thus to obviate its contemplated closing in July next. The college was given its distinctive character by Profs. Armstrong, Ayrton, and Perry, who were followed by Profs. Meldola and Silvanus Thompson, and the educational methods they introduced were both practical and sound, with the result that every student who took advantage of the opportunities afforded him was well equipped for his work in life. The college was founded by the City and Guilds of London Institute, and has in every wav been worthy of its founders. In the last financial year the expenditure was about $12,400 l$., of which about $7600 l$. was contributed by the institute and $4800 l$. was received in students' fees. It will thus be seen that the students' fees were nearly 40 per cent. of the income expended, which is a much No. 2667 , VOL. IO6] higher ratio than in universities and colleges generally. The average proportion of tuition fees in universities and colleges in receipt of State aid in England and Wales is 28 per, cent., and in the United States io per cent. Assuming that the City and Guilds Institute contribution is continued, a sum of at least $5000 l$. a year additional is required to enable the college to continue its work, and double that annual amount would not be too much to pay to secure its development. The defence committee has a strong case to put before the City Companies and the public, and it invites all who are interested in the preservation of the college to become members. Applications, with an entrance fee of $2 s$. $6 d$., should be sent to Dr. Atkinson, Finsbury Technical College, Leonard Street, E.C.2.

\section{Societies and Academies.}

\section{LONDON.}

Royal Society, November 25.-Sir J. J. Thomson, president, in the chair.-Prof. L. Hill : The growth of seedlings in wind. Mustard-and-cress seeds have been grown on lamp-wicks in a continuous wind of approximately 5 metres a second, and the control seeds in still air. The seeds grown in the wind are stunted and bent, and contain less water, more ash, less protein, and, presumably, more cellulose. To counterbalance the drying effect of the wind the seeds have been irrigated with water, and to balance the cooling effect of the wind due to evaporation this water has been warmed, so that a part of the irrigated wick in the wind has been as warm as, or warmer than, the control wick. By the combining effect of thorough wetting and warming the growth of the seeds in wind has been made much more nearly equal to that of the control. While the right amount of moisture is the most important factor, the cooling of the germinating seeds by the wind is also a factor in explaining the stunting of growth in wind-swept places.-Prof. P. T. Herring: The effect of thyroidfeeding and of thyroparathyroidectomy upon the pituitrin content of the posterior lobe of the pituitary, the cerebro-spinal fluid, and blood. (I) Neither thyroid-feeding nor thyroparathyroidectomy in cats affects the pituitrin load of the posterior lobe: of the pituitary body as tested by the action of similar strengths of extract upon the rat's uterus and the blood-pressure of the pithed cat. (2) There is no evidence of the presence of pituitrin in the cerebrospinal fluid of the fourth ventricle in normal, thyroidfed, and thyroparathyroidectomised cats. (3) The defibrinated blood of normal, thyroid-fed, and thyro. parathyroidectomised cats has no appreciable dction on the rat's uterus. The blood of thyroid-fed cats has a greater depressor action upon the circulation of an anæsthetised cat than has the blood of the normal animal. The blood of thyroparathyroidectomised cats has a pressor effect upon the circulation accompanied by contraction of the kidney and a diminution in the secretion of urine.-W. A. Jolly : Reflex times in the South African clawed frog. The reflex times of the homonymous and heteronvmous reflexes in the hind limbs of the spinal clawed frog have been measured at temperatures ranging from $14^{\circ} \mathrm{C}$. to $30^{\circ} \mathrm{C}$. The average heteronymous time (66 observations) is $18.7 \sigma$ (0.0187 second). The average homonymous time (68 observations) is $14.9 \sigma$. That is to sav, the crossed reflex time is longer than the same-side reflex time by $3.8 \sigma$. -Prof. J. A. Gunn and R. St. A. Heathcote: Cellular immunity. Observations on natural and acquired immunity to cobra venom. (a) Natural. Immunity.- 